\title{
Nutritional characteristics and health effects of regional cuisines in China
}

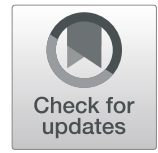

Na Zhang ${ }^{1,2}$ and Guansheng Ma ${ }^{1,2^{*}}$ (D)

\begin{abstract}
Background and objectives: Cuisine is the characteristic manifestation of the regional culture of Chinese food, which was formed and developed along with the distribution of physical geography and environment, the development of productivity and economy, cultural environment, ethnic food diversity, religion, and psychological and physiological factors. With the rapid development of the economy, food industry, and catering industry, various local cuisines learn from each other and develop greatly. The health consciousness of Chinese residents has gradually increased, and the requirements for nutrition and health of cuisine have also become higher and higher. The nutritional characteristics of regional cuisines and their effects on human health are increasingly being studied by scientists. The development of cuisine is facing new opportunities and challenges. It is necessary to understand the nutrition and health characteristics of cuisine and to take measures to reform and innovate the development of cuisines. The primary purposes of this paper are to introduce the formation and development of cuisines, to analyze the nutritional characteristics and health effects of four most influential regional cuisines-Sichuan Cuisine, Jiangsu cuisine, Shandong cuisine, and Cantonese, and to propose suggestions on future reform and innovation of cuisines.

Methods: An online search with the following keywords of Chinese language and English language (cuisine OR dietary OR food) and (Chinese OR China) and (health OR diseases OR nutrition) was performed between January 1980 and September 2019. Multiple databases were used including CNKI, WanFang, PubMed, Health and Medical Collection, LWW, and OVID. The focus was on Chinese studies about cuisine, nutritional characteristics, and health but drawing on literature all over the world. Then, nutritional characteristics and health effects of regional cuisines in China in these related literatures were analyzed and summarized in this paper.

Results and conclusions: Different cuisines have their specific nutritional advantages and disadvantages. The health statuses of the residents are closely associated with the dietary structure and food composition in regional cuisines. Regional cuisines need to be reformed and innovated ceaselessly to promote national health. It is necessary to adopt a scientific cooking method, increase food consistency and variety, and develop healthy dishes. The awareness of the nutrition and health among chefs and residents should be enhanced. The safety and hygiene of the restaurants should be strengthened in order to adapt to the transformation of the dining mode and to further standardize the evaluation criterion of dish.
\end{abstract}

Keywords: Regional cuisines, Ethnicity of food, Original food ingredients, Cooking methods, Nutrition, Health

\footnotetext{
* Correspondence: mags@bjmu.edu.cn

${ }^{1}$ Department of Nutrition and Food Hygiene, School of Public Health, Peking

University, 38 Xue Yuan Road, Hai Dian District, Beijing 100191, China

${ }^{2}$ Laboratory of Toxicological Research and Risk Assessment for Food Safety,

Peking University, 38 Xue Yuan Road, Hai Dian District, Beijing 100191, China
}

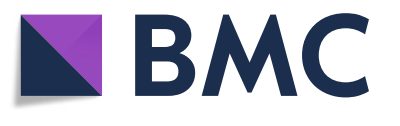

(c) The Author(s). 2020 Open Access This article is distributed under the terms of the Creative Commons Attribution 4.0 International License (http://creativecommons.org/licenses/by/4.0/), which permits unrestricted use, distribution, and reproduction in any medium, provided you give appropriate credit to the original author(s) and the source, provide a link to the Creative Commons license, and indicate if changes were made. The Creative Commons Public Domain Dedication waiver (http://creativecommons.org/publicdomain/zero/1.0/) applies to the data made available in this article, unless otherwise stated. 


\section{Introduction}

China has a long history, vast territory, and abundant resources; is the world's largest population; and has many ethnic groups. The natural conditions, living habits and lifestyles, economic and cultural development, and ethnic food diversity of various regions were different, which formed unique cooking methods, traditional food, eating customs, and diet patterns. Regional dietetic culture is gradually formed in various regions, and "cuisine" is the characteristic manifestation of the regional culture of Chinese food.

The two major flavors of the north and the south appeared as early as the Spring and Autumn, in the Tang and Song Dynasties, and two major flavor factions of Southern food and Northern food had been formed. In the early Qing Dynasty, four most influential regional cuisines had been formed: Shandong cuisine (flavored dishes covering some northern regions), Jiangsu cuisine (flavored dishes covering the regions of Jiangsu and Zhejiang), Cantonese cuisine (flavored dishes covering the regions of Guangdong), and Sichuan cuisine (flavored dishes covering the regions of Sichuan). At the end of the Qing Dynasty, the major additions to the previous four cuisines were Zhejiang cuisine, Fujian cuisine, Hunan cuisine, and Anhui cuisine, generally known as "eight major cuisines" (Fig. 1). "Ten major cuisines" began to appear after Beijing and Shanghai cuisine joined. There is a variety of famous dishes in various cuisines, with various ingredients, different cooking methods, and different flavors and nutritional characteristics, and their effects on health are also different.

With the rapid development of the economy, food industry, and catering industry, various local cuisines learn from each other and develop greatly. The health consciousness of Chinese residents has gradually increased. At the same time of pursuing delicious dishes, the requirements for nutrition and health of cuisine have also become higher and higher. The development of cuisine is facing new opportunities and challenges. It is necessary to understand the nutrition and health characteristics of cuisine, to take measures for the future reform and innovation of cuisines.

The primary aim of this paper is to introduce the formation and development of cuisines, to analyze the nutritional characteristics and health effects of the four most influential regional cuisines (Sichuan cuisine, Jiangsu cuisine, Shandong cuisine and Cantonese cuisine), and to propose suggestions on future reform and innovation of cuisines.

An online search with the following keywords of Chinese language and English language (cuisine OR dietary OR food) and (Chinses OR China) and (health OR diseases OR nutrition) was performed between January 1980 and September 2019. Multiple databases were used including CNKI, WanFang, PubMed, Health and Medical Collection,
LWW, and OVID. The focus was on Chinese studies about cuisine, nutritional characteristics, and health, but drawing on literature all over the world. Then, nutritional characteristics and health effects of regional cuisines in China in these related literatures were analyzed and summarized in this paper.

\section{The formation and development of regional cuisines}

There are many factors influencing the formation and development of the regional cuisines, including the distribution of physical geography and environment, cultural environment, and the psychological and physiological factors [1].

\section{Distribution of physical geography and environment}

In China, the landscapes vary significantly across its vast width. In the east, there are extensive alluvial plains, while in the north, there are high plateaus and broad grasslands; in the south, there are hills and low mountains; in the central-east, there are China's two major rivers, the Yellow River and the Yangtze River; in the west, there are major mountain. In China, the climate is mainly dominated by dry seasons and wet monsoons, which lead to pronounced temperature differences between winter and summer. In the winter, northern winds coming from higher-latitude areas are cold and dry; in summer, southern winds from lower-latitude areas are warm and moist. The climate in China varies in different regions due to the highly complex topography. The altitude also varies across different regions. All the above physical geography and environments result in the discrepancies on the mode of agricultural production, crop planting structure, agricultural species, original food ingredients, flavor preference, and cooking method, which play important roles in the formation and development of regional cuisines. An investigation suggested that geographical distance alone was a more crucial factor than climate for understanding the evolution and similarity among cuisines [2].

\section{Development of productivity and economy}

In ancient times, due to the low level of economic development, the backward means of transportation, and communication, agriculture was based on the family as a unit; the original food ingredients mainly came from local area; the scope of production activities was also limited. Eventually, eating habits were gradually inherited and became dietary customs. As the saying goes, people live from what the land can provide. With the improvement of productivity, the cuisine style has been evolving and local flavors had gradually formed in the political, economic, transportation, and cultural centers of different regions. With the prosperity of the economy and the development of transportation, food raw 


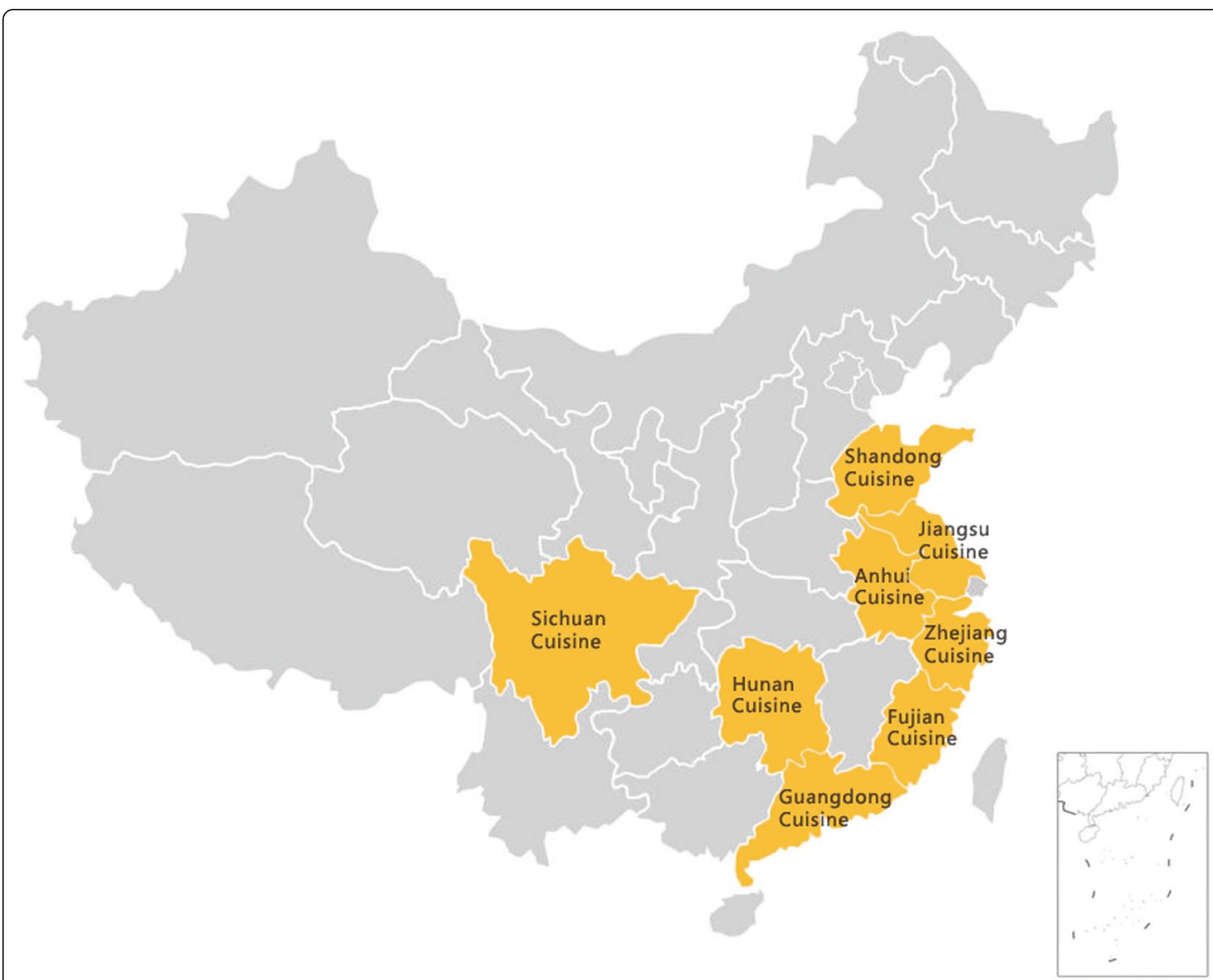

Fig. 1 Geographical distribution of eight cuisine in China. The generally known "eight major cuisines" were cuisines as follows: Shandong cuisine (flavored dishes covering some northern regions), Jiangsu cuisine (flavored dishes covering the regions), Cantonese cuisine (flavored dishes covering the regions of Guangdong), Sichuan Cuisine (flavored dishes covering the regions of Sichuan), Zhejiang cuisine (flavored dishes covering Zhejiang), Fujian cuisine (flavored dishes covering Fujian), Hunan cuisine (flavored dishes covering Hunan), and Anhui Cuisine (flavored dishes covering Anhui)

ingredients began to circulate around, cooking technology continued to be improved, and famous delicious dish formed, all of which laid the foundation for the formation of cuisine. The level of productivity and economic development also promote the spread of food culture, such as in ancient Yangzhou, during the glorious age of Tang Dynasty, with the transportation convenience of "salt" and "groove" center in the Ming and Qing Dynasties, "Huai-Yang flavor" was becoming popular the country; the influence of Jiangsu cuisine expanded rapidly. With the process of reform and opening up, Guangdong's economy developed rapidly; at the same time, Guangdong cuisine has become popular throughout the country.

\section{Ethnicity on food, religion, and cultural environment}

The religious beliefs and folk customs of different ethnic groups in different regions also affect the selection of original food ingredients and edible methods of food for the local residents. For example, the spread of Buddhism has promoted the popularity of vegetarian customs, and the cultivation and cooking techniques of vegetable, fruit, and bean products have been improved constantly as well. In the Northern and Southern Dynasty, Jiangsu Buddhism developed rapidly in Jiangsu area, as there are "vegetarian diet banquet" in Jiangsu cuisine. In addition, the origin and development of Taoism also made Sichuan get promotion. Taoism focus on diet in health preserving and treatment, which 
made the Chinese medicinal diet and cooking technology with little condiments got a development. "Ginkgo stewed chicken" is a representative of Sichuan cuisine. The animal food for people with ethnic customs, such as the Islamic ethnic group, are mainly cattle and mutton, and the Muslim dishes and pastry-making skills have been developed.

Different ethnic groups also have different eating habits. Manchu family dedicates the blessing and lucky meat to the honorable guests when sacrificing or celebrating. Fishing and hunting are the main sources of food and clothing for the Hezhe ethnic group. Hand-grasping sheep meat is a traditional favorite food by Mongolian herdsmen. Some southwestern ethnic groups like to eat insects, crickets, and some other insects.

The regional history and culture lay the foundation of the diet culture. The prototype of Shandong cuisine can be traced back to the Spring and Autumn Period. In the Spring and Autumn Period, in the state of Lu, Confucius proposed a diet concept of "very fussy about food," which involved duration and degree of heating in the process of cooking food, condiments, food hygiene, diet etiquette, and other aspects. After that, Mencius proposed a diet concept of "food and ambition - food and equivalent labor - food and morality and etiquette." Both two concepts are called "Confucius-Mencius food principles" collectively, which marked the formation of Chinese diet culture and laid a theoretical foundation for the formation and development of Shandong cuisine.

\section{Psychological and physiological factors}

The Chinese nation is a nation that attaches importance to history and tradition. Regional custom formed through the constant inheritance by generations for a long time. The fixed and regular lifestyle, dietary habits, and psychological factors make the food characteristics of various regions have a certain stability and historical inheritance. From a physiological point of view, because of long-term intake of certain types of food, human digestive systems have also changed gradually, forming the adaptability to regional cuisines.

\section{Nutritional characteristics of regional cuisines and health effects}

In a survey involving 538 subjects aged 50-60 years from 4 rural areas (representing the 4 major cuisines: Sichuan Cuisine, Shandong cuisine, Cantonese cuisine, Jiangsu cuisine, respectively), it was demonstrated that there were significant differences on the frequency, amount of food intake, and dietary patterns among the 4 cuisines [3]. Due to the different original food ingredients, cooking methods, flavoring additives, and nutritional characteristics, health effects of regional cuisines may be different. The nutritional characteristics of regional cuisines and their effects on human health are increasingly being studied by scientists. The characteristics of regional cuisines are shown in Table 1.

\section{Sichuan cuisine \\ Original food ingredients, flavor, and cooking methods}

Sichuan has always enjoyed the reputation of being a "Heavenly Land of Plenty" with vertical and horizontal rivers and rich products and remains green throughout the year. Sichuan cuisine is famous both at home and abroad with a wide variety and wide range of cooking ingredients. There are wild game from mountain areas, aquatic products from rivers, a variety of tender and delicious poultry and animal meat, plenty of fresh vegetables, mushroom, bamboo shoot, and fungus in the four seasons. There are also a wide variety of fine-textured fermented and cultivated condiments, such as Zigong well salt, Neijiang white sugar, Langzhong Baoning vinegar, Deyang soy sauce, Pixian bean paste, Maowen and Chengdu pepper, Xufu sprouts, and Nanchong Dongcai. All the above original food ingredients provide a good basis for the delicious dishes with deep and rich flavors in Sichuan cuisine. Cooking methods of Sichuan cuisine include stir-frying, pan-frying, braising, dry-frying, deepfrying, stewing, smoking, simmering in a covered pot over a slow fire, baking on a pan, quick-scalding, salting, and stewing in soy sauce. There are seven tastes: sour, sweet, spicy hot, spicy, bitter, salty, and aroma, and eight flavors: fish-flavored, sour and hot, spicy and hot, odd taste, pepper and chili, red camphor oil, ginger juice, and home-cooked taste.

\section{Nutritional values and health effects}

There is a variety of dishes in Sichuan cuisine with abundant nutritional values, For example, spicy diced chicken with peanuts, mapo tofu (stir-fried tofu in hot sauce), and fish filets in hot chili oil are rich in protein and fat; Sichuan Dandan noodles with peppery sauce are very rich in carbohydrates; some Sichuan cuisine are rich in vitamins, minerals, water, and dietary fiber. Nutrition in Sichuan cuisine is helpful to maintain the survival, growth of body, and normal physical activity. In addition, there are many fungus food containing phytochemicals, such as fungi polysaccharides, which are beneficial for health. However, there are some nutritional disadvantages. Sichuan cuisine emphasizes the use of condiments, with more usage of salt and condiments; edible oil was added excessively when cooking, and many dishes are cooked with animal viscera, which contains more fat and cholesterol; much of food are preserved in a salted way, and many dishes are cooked with salt processed food in $\mathrm{Si}$ chuan. In a survey about the condiment consumption among 3078 parents of primary and secondary school 
Table 1 Characteristics of the four cuisines in China

\begin{tabular}{|c|c|c|c|c|c|c|}
\hline Cuisines & Region & Flavor & $\begin{array}{l}\text { Original food } \\
\text { ingredients }\end{array}$ & Cooking methods & Condiments & Representative dishes \\
\hline $\begin{array}{l}\text { Sichuan } \\
\text { Cuisine }\end{array}$ & $\begin{array}{l}\text { Chengdu, } \\
\text { Chongqing }\end{array}$ & $\begin{array}{l}\text { Taste: sour, sweet, } \\
\text { spicy hot, spicy, bitter, } \\
\text { salty, and fragrant; } 8 \\
\text { flavors: fish-flavored, } \\
\text { sour and hot, spicy } \\
\text { and hot, odd taste, } \\
\text { pepper and chili, red } \\
\text { camphor oil, ginger } \\
\text { juice and home- } \\
\text { cooked taste }\end{array}$ & $\begin{array}{l}\text { Game; aquatic } \\
\text { products; a variety of } \\
\text { tender and delicious } \\
\text { poultry and animal } \\
\text { meat; plenty of fresh } \\
\text { vegetables, } \\
\text { mushroom, bamboo } \\
\text { shoot, and fungus }\end{array}$ & $\begin{array}{l}\text { Stir-frying, pan-frying, } \\
\text { braising, dry-frying, } \\
\text { deep-frying, stewing, } \\
\text { smoking, simmering } \\
\text { in a covered pot over } \\
\text { a slow fire, baking on } \\
\text { a pan, quick-scalding, } \\
\text { salting, and stewing in } \\
\text { soy sauce }\end{array}$ & $\begin{array}{l}\text { Chinese prickly } \\
\text { ash, hot peppers, } \\
\text { shallot, ginger, } \\
\text { garlic, capsicum, } \\
\text { vinegar, bean } \\
\text { paste }\end{array}$ & $\begin{array}{l}\text { Sichuan hotpot, } \\
\text { double-cooked pork, } \\
\text { mapo tofu, fish filets } \\
\text { in hot chili oil, spicy } \\
\text { diced chicken with } \\
\text { peanuts }\end{array}$ \\
\hline $\begin{array}{l}\text { Jiangsu } \\
\text { cuisine }\end{array}$ & $\begin{array}{l}\text { Nanjing, Huiyang, } \\
\text { Suzhou, Wuxi }\end{array}$ & $\begin{array}{l}\text { Sweet, salt, and } \\
\text { especially pure, } \\
\text { freshness, and } \\
\text { mildness }\end{array}$ & $\begin{array}{l}\text { Aquatic products, } \\
\text { variety of vegetables }\end{array}$ & $\begin{array}{l}\text { Stewing, braising, } \\
\text { simmering, warming }\end{array}$ & $\begin{array}{l}\text { Salt, sugar and } \\
\text { yellow rice, or } \\
\text { millet wine }\end{array}$ & $\begin{array}{l}\text { Water melon chicken, } \\
\text { brine-boiled duck, } \\
\text { sweet and sour man- } \\
\text { darin fish, duck } \\
\text { wrapped in shark fins, } \\
\text { fireside broth }\end{array}$ \\
\hline $\begin{array}{l}\text { Shandong } \\
\text { cuisine }\end{array}$ & $\begin{array}{l}\text { Jining, Jinan, } \\
\text { Jiaodong Peninsula } \\
\text { (Qingdao, Yantai, } \\
\text { Weihai) }\end{array}$ & $\begin{array}{l}\text { Salt, pure, and umami } \\
\text { oriented }\end{array}$ & $\begin{array}{l}\text { Abundant peanuts, } \\
\text { wheat, corn, sweet } \\
\text { potatoes, sorghum, } \\
\text { millet, soya beans; } \\
\text { varieties of } \\
\text { vegetables and fruits; } \\
\text { huge products of } \\
\text { seafood }\end{array}$ & $\begin{array}{l}\text { Quick frying, boiling, } \\
\text { frying, deep-frying, } \\
\text { quick frying with corn } \\
\text { flour, frying and sim- } \\
\text { mering, stewing, stuff- } \\
\text { ing, roasting }\end{array}$ & $\begin{array}{l}\text { Sauce paste, } \\
\text { fistulous onion, } \\
\text { and garlic }\end{array}$ & $\begin{array}{l}\text { Nine-coiled braised } \\
\text { pig intestine in } \\
\text { brown sauce, stir- } \\
\text { fried large yellow } \\
\text { croaker with sugar } \\
\text { and vinegar, stir-fried } \\
\text { sea cucumber with } \\
\text { green onions, stir- } \\
\text { fried pig's kidney, } \\
\text { pull-out silk sweet } \\
\text { potato with caramel- } \\
\text { ized sugar }\end{array}$ \\
\hline $\begin{array}{l}\text { Cantonese } \\
\text { cuisine }\end{array}$ & $\begin{array}{l}\text { Guangzhou, } \\
\text { Chaozhou, } \\
\text { Dongjiang }\end{array}$ & $\begin{array}{l}\text { Mild, fresh, natural } \\
\text { and slightly sweet, } \\
\text { sour, bitter, spicy }\end{array}$ & $\begin{array}{l}\text { Delicacies of } \\
\text { mountain and sea } \\
\text { and a rich variety of } \\
\text { fresh vegetables }\end{array}$ & $\begin{array}{l}\text { Stir frying and } \\
\text { steaming }\end{array}$ & $\begin{array}{l}\text { Sweet and sour } \\
\text { sauce, oyster } \\
\text { sauce, soy sauce, } \\
\text { white brine dark } \\
\text { plum sauce, } \\
\text { cranberry sauce, } \\
\text { barbecue sauce } \\
\text { and fish sauce }\end{array}$ & $\begin{array}{l}\text { Roast suckling pig, } \\
\text { dry-fried beef and } \\
\text { noodles, barbequed } \\
\text { pork (char siu), small } \\
\text { pan rice, brine-soaked } \\
\text { duck }\end{array}$ \\
\hline
\end{tabular}

The flavor, original food ingredients, cooking methods, condiments and representative dishes of four cuisines in China is summarized and described in this table

students in Chengdu, the results showed that the rate of using low sodium salt usually were merely $9.9 \%$ [4]. The consumption rate of soy sauce, monosodium glutamate/ chicken essence, bean paste, soy cheese, pickles, peanut butter, and salad (over seven times a week) among these participants were $19.7 \%, 27.9 \%, 12.5 \%, 2.6 \%, 3.3 \%$, and $2.1 \%$, respectively [4]. The study on the food consumption pattern of elderly people in four cuisine areas of China demonstrated that the animal oil consumption in Chengdu, Sichuan was highest (35 g) among four regions, which was higher than the recommended amount of edible oil ( $25 \mathrm{~g})$ in Dietary Guidelines for Chinese Residents 2016 [3]. A review of the epidemiological studies demonstrates that hypertension was associated with excess dietary sodium [5]. In a cross-sectional study with 19,760 residents among adults aged 18 and above, it was shown that the total detection rate of prehypertension was $32.9 \%$ in Wuhou District of Chengdu (in Sichuan) [6]. The data from chronic diseases and nutrition supervision in $\mathrm{Si}$ chuan province showed that the prevalence rate of hypertension among adults aged 18 years old and above was $27.7 \%$, which was higher than the nationwide rate (25.2\%). "Animal fat" has been classified into the unhealthy group according to the degree of unsaturation compared to "vegetable oil." It has been suggested that excessive intake of animal fat may increase the risk of cardiovascular disease, fatty liver, and obesity in many studies [7]. However, due to numerous factors, the mortality of cardiovascular and cerebrovascular diseases and the rate of dyslipidemia rate were relatively lower compared to most other regions except for the southeast coastal area in China [8]. Salt processed food may contain carcinogenic $\mathrm{N}$-nitroso compounds in a condition with a high level of salt. N-nitrosamines, classified as carcinogens by IARC (International Agency for Research on Cancer) and US EPA (Environmental Protection Agency), may produce in salt processed food. It has been reported by some studies that excessive salt processed food intake was positively associated with an increased risk of gastric cancer and liver cancer [9]. In a hospital-based case-control study with 107 
newly diagnosed cases with histological confirmation of gastric cancer and 209 controls in China, it was concluded that compared to the high-intake group with no consumption of salt processed foods, salted processed food were significantly associated with increased risk of gastric cancer [9]. In addition, there was a dose-response relationship with salt taste preference and gastric cancer [9]. As the Report on Chinese Residents' Nutrition and Chronic Disease (2015) shown, the standardized mortality rate of liver cancer in Southern China, Chongqing, and Sichuan was higher than those in other areas with statistical significance [10].

\section{Jiangsu cuisine (and Zhejiang cuisine)}

\section{Original food ingredients, flavor, and cooking methods}

The Jiangsu and Zhejiang cuisines have many similarities, so the two are often referred to one style of cuisine collectively. Jiangsu and Zhejiang areas are located in the eastern coastal areas of China, with rivers interwoven, such as the Changjiang River and the Grand Canal from Hangzhou to Beijing. The special geographical environment in Jiangsu and Zhejiang produces a vast variety of food. Jiangsu and Zhejiang are fish and rice country with rich products and abundant dietary resources, which are beneficial to food diversification and balance diet. Famous aquatic products include three fresh delicacies of the Changjiang River (sturgeon, the long-tailed anchovy, and catfish), Taihu Lake silver fish, Yangcheng Lake fresh water crab, Longchi Lake crucian, and other varieties of aquatic food. Vegetables include Xianghu Water Shield, Huaian cattail, Baoying lotus, Chinese chestnut, gorgon fruit, Zizania aquatic, winter bamboo shoots, water chestnut, and so on. The cooking method of Jiangsu and Zhejiang cuisine is more appropriate, for the reason that food are mainly cooked with water as medium. The features of Jiangsu and Zhejiang cuisine include the following: the original food ingredients are mainly aquatic products from rivers, lakes, and the sea; the major cooking methods are stewing, braising, simmering, and warming, which can preserve original flavors and nutrients of food; the flavor of dishes are sweet, salty, and especially pure, fresh, and mild. The advantages of water as a medium include the following. The temperature of cooking is low, which is beneficial to the protection of nutrients and can reduce the production of harmful substances produced by high temperature.

\section{Nutritional values and health effects}

Aquatic products, soy products, bamboo shoots, fungi, and fresh vegetables are commonly consumed in Jiangsu and Zhejiang cuisine [11]. Aquatic products are major source of polyunsaturated fatty acid (PUFA), vitamins (vitamin A and D), and minerals (zinc, selenium, iron, and iodine). Studies demonstrated that adequate fish intake may reduce the risk of cardiovascular disease and stroke and reduce the risk of dementia and cognitive dysfunction and age-related macular degeneration [12]. Soy products are good source of high-quality protein, essential fatty acid, vitamin E, and phytochemicals (isoflavones, phytosterols, and saponins). It has been suggested that sufficient legume and legume product consumption may reduce the risk of breast cancer, osteoporosis, lung cancer, hypertension, hyperlipidemia, obesity, prostate cancer, colon cancer, and gastric cancer [12]. Fresh green vegetables are good sources of vitamins, minerals, and dietary fiber. Cruciferous vegetables contain the phytochemicals glucosinolates, such as sinigrin and sulphoraphane, which have been suggested to be beneficial for preventing cancer formation. Edible bamboos are well known in Zhejiang cuisine, and there are rare and expensive venison and many types of fungi. Edible bamboos are also good sources of dietary fiber, vitamin B group, copper, selenium, and potassium [13]. Studies suggested that increasing the consumption of vegetables could reduce the risk of all-cause mortality, the incidence and the death rate of cardiovascular and cerebrovascular diseases, and the risk of partial cancer (esophageal, colon, liver, nasopharyngeal carcinoma); green leafy vegetables could reduce the risk of diabetes and lung cancer. Increasing the consumption of cruciferous vegetables may reduce the risk of lung, gastric, and breast cancer [12]. In a survey involving 538 subjects aged 50-60 years from four rural areas representative for the four cuisines, it was shown that the frequency of aquatic food intake, the amount of mushroom, and algae consumption in Yangzhou and Changshu (two cities in Jiangsu) was more than that in other regions. In addition, the amount of legume and legume product consumption in Yangzhou was higher than that in other regions [3]. According to the data from Chinese Nutrition and Health Survey of Jiangsu Province from 2010 to 2012, the average daily intakes of aquatic products and legume products were $44.9 \mathrm{~g}$ and $14.8 \mathrm{~g}$, respectively, which was higher than the national survey data (23.7 $\mathrm{g}$ and $10.9 \mathrm{~g}$ ), but had not reached the recommended amount (40-75 g and 25-35 g) in Balanced Diet Pagoda for Chinese Residents. The Report on Chinese Residents' Nutrition and Chronic Disease (2015) showed that the mortalities of cardiovascular disease, stroke, and ischemic heart disease were lower in southeast coastal area (including Jiangsu and Zhejiang) than those in other regions; among them, the mortality of ischemic heart disease in Zhejiang was the lowest [10].

\section{Shandong cuisine}

Original food ingredients, flavor, and cooking methods

Shandong, a northern coastal province of China, locates in Jiaodong Peninsula, with the Yellow River meandering through the center, between Bohai and the Yellow Sea. 
There are mountains and rivers in Shandong province. The climate is optimum, and natural products are abundant. Shandong abounds in peanuts, wheat, corn, sweet potatoes, sorghum, millet, soya beans, and so on. There are varieties of vegetables and fruits, such as Jiaozhou cabbage, Laiwu ginger, Zhangqiu onion, Cangshan garlic, Weifang radish, Yantai apple, and Laiyang pear; the products of seafood are huge, such as sea cucumber, abalone, shrimp, scallop in shell, genuine porgy, yellow croaker, and jellyfish; condiments have a profusion of varieties, such as Linyi eight treasures fermented soya bean, Luokou vinegar, Ji'nan soy sauce, and Jimo rice wine. The cooking methods of Shandong cuisine are expert in quick frying, boiling, frying, deep-frying, quick frying with corn flour, frying and simmering, stewing, stuffing, and roasting; condiments such as sauce paste, fistulous onion, and garlic are commonly used, and the characteristics of flavor are "salt, pure, and umami oriented." Shandong cuisine is good at cooking seafood with the original flavor preserved.

\section{Nutritional values and health effects}

Shandong cuisine is well known for its variety of seafood, including scallop, prawn/shrimp, clam, sea cucumber, and algal food. Seafood is rich in high-quality protein, unsaturated fatty acids (its impacts on health have been mentioned), and minerals, such as iodine and sodium (its impacts on health have been mentioned). Adequate consumption with shellfish was probably associated with lower incidence of cardiovascular events [14], type 2 diabetes mellitus (T2DM) [15], thyroid carcinoma [16], and prostatic carcinoma [17], but a higher incidence of hyperuricemia [18]. Algae consumption reduces the risk of T2DM [19] and thyroid carcinoma [20] and is beneficial for maintaining normal blood pressure [21]. Adequate shrimp consumption may reduce the risk of hypertension. Tsingtao Beer is famous in Shandong, but more beer intake increases the risk of hyperuricemia [22] and abdominal obesity [23]. In a survey with 2036 adults aged 18 to 69 years in 20 counties, it was shown that iodine nutrition status of inhabitants in the whole province was more than adequate or excessive with a discrepancy in landforms and topography, geographical position, urban and rural, and gender. Sodium intakes remained high among residents in Shandong province, and the largest sources were condiments in a survey with 2184 subjects aged 19 69 years old in Shandong [24]. The consumption of fish and shrimp was higher in Shandong in 2009 (72.4 g) and was obviously higher than the national data in 2012 (23.7 g) [10, 25]. According to the data of surveillance on behavioral risk factors for chronic diseases among residents in Shandong, it was indicated that the average daily alcohol intake of the subjects was $28.2 \mathrm{~g}$ in 2013 [26], which was higher than the national survey data (annual per capita alcohol intake, $3 \mathrm{~L}$ ) in 2012. According to the data of chronic disease and risk factor surveillance in Shandong in 2013 [10], the prevalence of hypertension was $29.5 \%$ and higher than the national survey data (25.2\%) [10]; the prevalence of T2DM was $8.3 \%$ and lower than national survey data $(9.7 \%)$ [27]. The standardized prevalence of hyperuricemia was $16.99 \%$ in Shandong coastal areas in 2009 [28], while the prevalence was $15.71 \%$ in Shandong inland areas in 2012 [29]; both of them were higher than the national survey data (8.4\%) in 2010 [30]. It is worthy to note that the prevalence of Graves disease in the Shandong coast area is $1.38 \%$, and the higher prevalence was associated with excessive iodine [31].

\section{Cantonese cuisine}

Original food ingredients, flavor, and cooking methods

Guangdong, located in the subtropical region and the southern tip of mainland China, remains green throughout the year with abundant rainfall and rich natural resources. Most of the delicacies are from mountains and seas, and there are a rich variety of fresh vegetables in each season in Guangdong. The factions of Guangdong cuisine are mainly composed of three parts: Guangzhou cuisine, Chaozhou cuisine, and Dongjiang Hakka cuisine. Guangzhou cuisine is the main representative of the Cantonese cuisine with the characteristic of wide range of original food ingredients, just like the saying "They eat everything with four legs except tables and everything that flies except airplanes." In Guangzhou cuisine, various wild game dishes with fresh original food ingredients, such as poultry, animals, insects, and fish, are unique and the flavors have a bias towards aroma, freshness, and sweetness. Chaozhou cuisine attaches great importance to the seasoning of the sauce and is good at cooking seafood and vegetable dishes. The main original food ingredients of Hakka cuisine are animal food, not seafood; the flavor of Hakka cuisine emphasizes tenderness, aroma, crisp, and salt with more edible oil and sauce when cooking; casserole is the common specialties. Overall, the cooking method was mainly stir-frying and steaming; sweet and sour sauce, oyster sauce, soy sauce, white brine dark plum sauce, cranberry sauce, barbecue sauce, and fish sauce were usually used as condiments; the characteristics of flavor in Cantonese cuisine are mild, fresh, natural, and slightly sweet. In addition, Cantonese cuisine attaches great importance to soup, dim sum, and tea.

\section{Nutritional values and health effects}

Soups are given much emphasis in Cantonese cuisine and cooked using chicken, duck, pork, and other raw ingredients with/without Chinese herbs according to the different seasons. Unlike other Chinese cuisines, soup was usually 
served before a meal. Soup may also contribute to total fluid intake for maintaining adequate hydration. In addition, the soup added with Chinese herbal medicines also have some health benefits according to the specific components [32]. People in Guangzhou also like to eat fish, which contains beneficial unsaturated fatty acids (its impacts on health have been mentioned). Drinking tea and eating dim sums have been a tradition among Cantonese people. Adequate drinking of tea reduces the risk of T2DM [33], cerebral apoplexy [34], cardiovascular diseases [35], ovarian cancer [36], and gastric cancer [37]. In a survey about fluid intake among 64 adults aged 18-60 years from 4 cities, it was indicated that water from soups in Guangdong was $267 \mathrm{~mL}$ (accounting for $41.8 \%$ of water from food), which was higher than those in Shanghai (133 $\mathrm{mL}, 9.0 \%)$ and Beijing (100 mL, 5.8\%) [38]. Statistics in 2014 showed that the output of tea in Guangdong was 74, $000 \mathrm{t}$, accounting for $3.5 \%$ of the total tea output in the country $(2,096,000 \mathrm{t})$, ranked ninth among all cities in China [39]. The per capita consumption of tea in the whole province ranks first in the country [39]. In a survey with 2976 residents above 3 years old in 7 districts of Guangzhou in 2011, it was shown that the aquatic product consumption was $60.5 \mathrm{~g} /$ day [40], and higher than the national survey data $(23.7 \mathrm{~g})$ [10]. It was worthy to note that more consumption of Cantonese salted fish was associated with increased risk of nasopharyngeal carcinoma [41]. According to the report of Nutrition and Health Survey among residents in Guangdong province in 2002-2012, it was shown that the rates of overweight, obesity, hypertension, and dyslipidemia were $26.2 \%, 9.9 \%, 21.4 \%$, and $39.7 \%$, respectively. All of these rates were lower than the national survey data $(30.1 \%, 11.9 \%, 25.2 \%$, and $40.4 \%$, respectively), while the rate of diabetes was $10.1 \%$ and higher than the national survey data (9.7\%) [10]. The cancer data of selected population-based cancer registries in Guangdong suggested that the top 5 incident cancers were lung, liver, female breast, colon, and nasopharyngeal cancers, and the top 5 death cancers were lung, liver, colon, stomach, and nasopharyngeal cancers in Guangdong in 2012 [42]. Nasopharyngeal carcinoma is not a common cancer in our country, and high incidence rate occurs in Southeast Asia and Southern China, especially in Guangdong [41].

\section{Future reform and innovation of regional cuisines}

With the development of economy and the improvement of people's health literacy, food is not only to meet the demand for physiological needs, but also to meet the demand for health. The "Healthy China 2030" Program Outline emphasizes the importance of promoting the construction of healthy China and improving the health level of the people. Outline of the Development of Food and Nutrition in China (2014-2020) pointed out that the food production in China cannot adapt to the nutritional needs; triple burden of malnutrition including undernutrition, hidden hunger and overweight and obesity existed simultaneously among residents; the knowledge of nutrition and health was sufficient. It is necessary to further ensure the effective supply of food, optimize the structure of food, and strengthen the improvement of the nutrition among residents. Regional cuisines need to be reformed and innovated with the times to promote national health.

\section{To improve awareness of the nutrition and health among chefs and residents}

Improving the knowledge level of chefs is a powerful guarantee for scientific cooking and developing healthy dishes. In addition, improving national nutrition and health awareness is powerful to guarantee reasonable meal and keep health.

\section{To adopt scientific cooking method, increase food consistency and variety, and develop healthy dishes} It is necessary to adopt more scientific cooking methods to reduce the damage to the nutrients of food raw ingredients. Condiments should be added reasonably with less salt, less sugar, and less edible oil. Increasing food consistency and variety is beneficial to health. In order to meet the needs of the balanced nutrient intake from dishes, healthy dishes should be developed combining the fresh food ingredients with seasonal variations in each place.

\section{To strengthen the supervision of the safety and hygiene} of the restaurants in order to adapt to the transformation of the dining mode

With the development of the economy and the improvement of income level, as well as the rapid development of catering industry, eight cuisines are not limited by geography. People can eat each type of regional cuisines in their own living region. Dining in a restaurant has become an important part of dining mode. With the rapid development of the network economy and electronic commerce, a new dining channel, online ordering, has also emerged as the times require. Both of dining in a restaurant and dining through online ordering can be classified as "out-of-home eating (OH eating)," which means that people choose to eat meals in restaurants, canteens, or restaurants, or buy food that can be eaten directly as meals from restaurants, canteens, supermarkets, and other places (excluding semi-finished products) or convenience and eat them at home. The ingredients and cooking methods differ in restaurant from at home, which may have adverse effects on health. The prevalence of $\mathrm{OH}$ eating among residents aged above 6 years old was $35.5 \%$ in 2012. It is necessary to strengthen the supervision of the safety and hygiene of the restaurants. 
To further standardize the evaluation criterion of dish In restaurant, the diet did not meet the balanced diet standard due to excess energy, protein, fat, and salt. Scientific evidences suggested that $\mathrm{OH}$ eating was positively associated with overweight and obesity among men adults [43]. There is also high risk of hypertension, high serum cholesterol level, diabetes, and other health hazards among $\mathrm{OH}$ eating residents [44]. The evaluation criterion is the key to ensure the health effects of food; thus, it is necessary to further standardize the evaluation criterion of dish.

\section{Conclusion}

Overall, the formation and development of regional cuisines are closely associated with the distribution of physical geography and environment, the development of productivity and economy, cultural environment, and psychological and physiological factors. Due to the different nutritional characteristics of regional cuisines, the health effects may be also different. To promote the health of the nations, regional cuisines should be reformed and innovated scientifically.

\section{Acknowledgements}

It is not applicable.

\section{Authors' contributions}

NZ wrote this manuscript. GM revised it. Both authors read and approved the final manuscript.

\section{Funding}

There is no fund.

\section{Availability of data and materials}

It is not applicable.

\section{Competing interests}

The authors declare that they have no competing interests.

Received: 6 October 2019 Accepted: 5 January 2020

Published online: 31 January 2020

\section{References}

1. Zhu YX, Huang J, Zhang ZK, Zhang QM, Zhou T, Ahn YY. Geography and similarity of regional cuisines in China. Plos One. 2013;8(11):e79161.

2. Lipman J. Chinese geography through Chinese cuisine. Soc Educ. 2010;74: $17-20$.

3. Zhao WH, You Y, Zhang X, Wang JL, Chen JS. Study on the food consumption pattern of elderly people in four "cuisine" areas of China. J Hygiene Res. 2002;31(1):34-7.

4. Song C, Ma GS, Liu AL, Guo HJ, Gong WY, Wu XW, et al. Analysis of consumption of condiments and salty foods among students' parents in Four Cities, China. Chin J Health Educ. 2015;4:348-53.

5. Patience $\mathrm{S}$. Understanding the relationship between salt intake and hypertension. Nurs Stand. 2013;27(18):45.

6. Yang FX, Hua JJ, Feng F, Yuan P. Study on risk factors of prehypertension among residents over the age of 18 in Wuhou District, Chengdu City. Chin J Dis Control. 2013;17(9):747-51.

7. Lecerf JM. Fatty acids and cardiovascular disease. Nutr Rev. 2009;67(5):27383.

8. Xu XY, Deng Y, Ji K, Chen XF, Zeng J, Yi GH, et al. Health status and epidemiological status of key chronic diseases in Sichuan province. J Dis Surveil. 2017;32(1):6-8.
9. Lin SH, Li YH, Leung K, Huang CY, Wang XR. Salt processed food and gastric cancer in a Chinese population. Asian Pac J Cancer Prev. 2014;15(13):5293-8.

10. National Health Commission. Report on the status of Chinese residents' nutrition and chronic diseases. Beijing: People's Health Publishing House; 2015.

11. Erlich R. Cultural and historical trends and influences of food, nutrition and cuisine on health and development. Asia Pac J Clin Nutr. 2004;13(2):125-30.

12. Chinese Nutrition Society. Food and health. Beijing: People's Medical Publishing House; 2016.

13. Li D, Premier R. Cuisine: Hangzhou foods and their role in community health and nutrition. Asia Pac J Clin Nutr. 2004;13(2):141.

14. Hlebowicz J, Drake I, Bo G, Sonestedt E, Wallström P, Persson M, et al. A high diet quality is associated with lower incidence of cardiovascular events in the Malmö diet and cancer cohort. Plos One. 2013;8(8):e71095.

15. Villegas R, Xiang YB, Elasy T, Li HL, Yang G, Cai H, et al. Fish, shellfish, and long-chain $\mathrm{n}-3$ fatty acid consumption and risk of incident type 2 diabetes in middle-aged Chinese men and women. Am J Clin Nutr. 2011;94(2):543.

16. Cléro É, Doyon F, Chungue V, Rachédi F, Boissin JL, Sebbag J, et al. Dietary iodine and thyroid cancer risk in French Polynesia: a case-control study. Thyroid. 2012;22(4):422.

17. Raimondi S, Mabrouk JB, Shatenstein B, Maisonneuve P, Ghadirian P. Diet and prostate cancer risk with specific focus on dairy products and dietary calcium: a case-control study. Prostate. 2010;70(10):1054.

18. Chang WC. Dietary intake and the risk of hyperuricemia, gout and chronic kidney disease in elderly Taiwanese men. Aging Male. 2011;14(3):195-202.

19. Lee HJ, Kim HC, Vitek L, Nam CM. Algae consumption and risk of type 2 diabetes: Korean National Health and Nutrition Examination Survey in 2005. Jutr Sci Vitaminol. 2010;56(1):13-8.

20. Michikawa T, Inoue M, Shimazu T, Sawada N, Iwasaki M, Sasazuki S, et al. Seaweed consumption and the risk of thyroid cancer in women: the Japan Public Health center-based prospective study. Eur J Cancer Prev. 2012;21 (3):254.

21. Wada K, Nakamura K, Tamai Y, Tsuji M, Sahashi Y, Watanabe K, et al. Seaweed intake and blood pressure levels in healthy pre-school Japanese children. Nutr J. 2011;10(1):83.

22. Yu KH, See LC, Huang YC, Yang CH, Sun JH. Dietary factors associated with hyperuricemia in adults. Sem Arthritis Rheum. 2008:37(4):243-50.

23. Bendsen NT, Christensen R, Bartels EM, Kok FJ, Sierksma A, Raben A, et al. Is beer consumption related to measures of abdominal and general obesity? A systematic review and meta-analysis. Nutr Rev. 2013;71(2):67.

24. Lu ZL, Zhang XF, Li JH, Zhang JY, Zhao WH, Ma JX, et al. Dietary sodium intakes and resources among residents in Shandong province. Chin J Prev Med. 2014;48(1):7-11.

25. Zhao XT. Investigation on dietary patterns and physical condition of urban and rural residents in Shandong: Shandong University; 2012.

26. Zhang GH, Lu ZL, Guo XL, Chen X, Xu CX, Tang JL, et al. Cross-sectional survey on drinking among residents aged 18 and older in Shandong province during 2013. Chin J Prev Med. 2017;51(5):450-2.

27. Zhang YC. Study on epidemic trend of chronic diseases and its risk factors in Shandong from 2004 to 2013: Shandong University; 2015.

28. Yan $S L$, Zhao SH, Li CG, Wang YG, Wang P, Wang ZC, et al. A five years follow up study on patients with gout and hyperuricemia. Chin J Endocrinol Metabol. 2011;27(7):548-52.

29. Cao LJ, Lin HY, Zhou J, Chen HY, Li YY, Wang Z. Prevalence and risk factors of hyperuricemia in Shandong Province. J Military Med. 2014;1 1:897-900.

30. Liu H, Zhang XM, Wang YL, Liu BC. Prevalence of hyperuricemia among Chinese adults: a national cross-sectional survey using multistage, stratified sampling. J Nephrol. 2014;27(6):653-8.

31. Yan SL, Wang YG, Wang F, Zhao SH, Yu XL. Relationship between iodine in urine and Graves disease along coastal district in Shandong. Chin J Endemiol. 2004;23(3):245-7.

32. Deng WX, Zhu JP, Xiao ZW, Zhang SH, Xie MZ. On development suggestions and current situation of medicined diet soup or decoction. J Tradit Chin Med Univ Hunan. 2015;35(12):23-6.

33. Zheng $X X, X u Y L, L i S H$, Hui R, Wu YJ, Huang XH. Effects of green tea catechins with or without caffeine on glycemic control in adults: a metaanalysis of randomized controlled trials. Am J Clin Nutr. 2013;97(4):750-62.

34. Arab L, Liu W, Elashoff D. Green and black tea consumption and risk of stroke: a meta-analysis. Stroke. 2009:40(5):1786.

35. Hartley L, Flowers N, Holmes J. Green and black tea for the primary prevention of cardiovascular disease. Cochrane Database Syst Rev. 2013;6(6): CD009934. 
36. Braem MG, Onland-Moret NC, Schouten LJ, Tjønneland A, Hansen L, Dahm CC, et al. Coffee and tea consumption and the risk of ovarian cancer: a prospective cohort study and updated meta-analysis. Am J Clin Nutr. 2012; 95(95):1172-81.

37. Huang Y, Chen H, Zhou L, Li G, Yi D, Zhang Y, et al. Association between green tea intake and risk of gastric cancer: a systematic review and dose-response meta-analysis of observational studies. Public Health Nutr. 2017:1-10.

38. Ma GS, Zuo JL, Li XH, Gao JM, Zhu WG, Ni HJ, et al. Food water sources analysis of adults in four cities of China in summer. Chin J Prev Med. 2011; 45(8):692-5.

39. Xu HJ. Study on competitiveness of tea culture industry in Guangdong: South China Agricultural; 2016.

40. Zhang YH, Li YY, He JY, Liang BH, Yu C, Zhang WW, et al. Food consumption and nutrients intake among residents in Guangzhou city. Chin J Public Health. 2017:33(6):969-72.

41. Luo XY. Epidemiological study of risk factors for new cases of nasopharyngeal carcinoma in Guangdong: Zhongshan University; 2009.

42. Meng RL, Xu YJ, Lin LF, Wei KR, Chen WQ, Zheng RT. Cancer incidence and mortality in 2012. Chin J Oncol. 2016;25(12):933-41.

43. Xia J, He YN, Zhuo Q, Yang XG. Status of dietary fat intake of Chinese residents in different dining locations and times. J Hygiene Res. 2016;45(2): 236-40.

44. Cao KK, He YN. Research progress on the effects of dining outside on human health. Chin J Food Nutr. 2014;20(1):67-71.

\section{Publisher's Note}

Springer Nature remains neutral with regard to jurisdictional claims in published maps and institutional affiliations.

Ready to submit your research? Choose BMC and benefit from:

- fast, convenient online submission

- thorough peer review by experienced researchers in your field

- rapid publication on acceptance

- support for research data, including large and complex data types

- gold Open Access which fosters wider collaboration and increased citations

- maximum visibility for your research: over $100 \mathrm{M}$ website views per year

At $\mathrm{BMC}$, research is always in progress.

Learn more biomedcentral.com/submissions 